\title{
SOBRE EL REFERENTE Y \\ LA TRANSFORMACIÓN NARRATIVA EN LAS NOVELAS DE CARLOS FUENTES Y GUSTAVO SAINZ
}

\author{
JOHN S. BRUSHW OOD \\ University of Kansas
}

En la novela mexicana reciente, la ciudad de México desempeña un papel muy especial que corresponde a su importancia como punto focal de la nación. El enfoque narrativo sobre la ciudad es variable de manera que la apreciación de la vida urbana va desde la idea del monstruo deshumanizador, pasando por la esperanza un poco romántica de triunfar-posiblemente en un contex to de alta sofisticación, hasta un concepto de la ciudad como realidad intimamente conocida. Este último punto de vista es el que define la ciudad en las novelas de Gustavo Sainz, por ejemplo, y de muchos otros escritores que han publicado sus novelas desde 1965 hasta ahora. Para estos novelistas la ciudad no es un mundo ajeno para conquistar. No es ni espantosa ni atractiva, sino simplemente cotidiana. El Distrito Federal es su provincia, su terruño: la vida de la ciudad es su manera de vivir.

Esta diferencia, entre la nueva significación de la ciudad, y la significación más tradicional, evidentemente tiene importancia temática. Por otro lado, la misma diferencia se relaciona, según mi modo de ver, con uno de los pasos de la transformación, el que pudiéramos llamar "la conceptualización de la historia". Ésta-la historia - consta del material narrable que el narrador transforma para hacer la narrativa que leemos. ${ }^{1}$ En términos semióticos, la narrativa que leemos es el significante, la historia es el significado, el referente es la realidad extratextual a la cual la historia y la narrativa se refieren.

\footnotetext{
1 Véase Gérard Genette, "Discours du récit", en Figures III (Paris: Seuil, 1972) o la versión en inglés, Narrative Discourse (Ithaca, N.Y.: Cornell University Press, 1979). La historia (histoire) es el material que el narrad or va a narrar. En el acto de narrar (la narración es el acto de narrar), el narrador emplea múltiples técnicas para transformar la historia. Mediante la narración el narrador crea la narrativa (récit).
} 
Generalmente, en el análisis de una obra de ficción, estudiamos las estrategias empleadas por el narrador en el acto de transformar la historia. ${ }^{2}$ Indudablemente tales estrategias-reconocidas por el narrador y el lectorproducen el fenómeno artístico. ${ }^{3}$ Por otro lado, me parece sumamente importante notar un acto de transformación que se efectúa entre la realidad extratextual (el referente) y la historia. Esta transformación ocurre como un aspecto del acto de comunicar, pero nada tiene que ver con las estrategias narrativas. Se trata de la conceptualización de la historia, acto en que el autor puede modificar la realidad extratextual. La modificación producida será algo como una definición del "autor implícito", de Wayne Booth. ${ }^{4}$

Cabe señalar que la ciudad de México es sólo una parte del referente de cualquiera de las novelas de Fuentes o de Sainz. Sin embargo, vale concentrarnos por el momento sobre este factor tan importante. Por eso, notaremos una afirmación, de parte de cada novelista, que ilumina la diferencia ya notada. Hablando con Emmanuel Carballo sobre la composición de La región más transparente, Fuentes dice lo siguiente:

Al escribir una novela tengo una visión del mundo, una visión de las cosas. Los personajes surgen de maneras muy distintas. En La región surgieron de un modo típico. Se trata de personajes representativos de los diferentes estratos sociales, de las distintas direcciones del espíritu mexicano. A veces no poseen vida propia ni destino personal: son piezas que manipulo para integrar el panorama de la sociedad mexicana de nuestros días. ${ }^{5}$

Al afirmar que tiene una visión del mundo, una visión de las cosas, el autor nos avisa que la historia en su primera novela será una versión de la realidad extratextual, ya ajustada según los conceptos del novelista. Sigue exponiendo que él está afuera de la circunstancia, manipulándola para ejemplificar su concepto de la realidad extratextual. Señala Fuentes que esto pudiera ser un error que trató de superar en La muerte de Artemio Cruz. Seguramente lo hizo. Sin embargo, el acto de predeterminación-en la primera novela de Fuentes-me parece importante en la trayectoria de su obra creativa y

\footnotetext{
2 Wolfgang Iser emplea el término "strategies" en The Act of Reading (Baltimore: The John Hopkins University Press, 1978). La idea de "estrategias' me parece más acertada que la de "técnicas", en lo que se refiere a la narración, porque subraya la importancia de una transformación para comunicarse con el lector. Iser señala, desde luego, que el lector tiene que reconocer las estrategias.

3 Iser aclara que el acto artístico es efectuado por el narrador. El lector comete el acto estético. 4 Véase Wayne Booth, The Rhetoric of Fiction (Chicago: University of Chicago Press, 1961).

5 Emmanuel Carballo, Diez protagonistas de la literatura mexicana del siglo XX (México: Empresas Editoriales, 1965), p. 436 (énfasis mío).
} 
volveremos más adelante al problema general de la diferencia entre la historia (el significado) y su referente. Por el momento, cabe notar específicamente cómo su manera de representar la ciudad influye en la carrera de Gustavo Sainz y cómo Sainz altera el concepto de la ciudad.

En una entrevista con Josefina Millán, efectuada aproximadamente diez años después de la entrevista Carballo-Fuentes, Sainz afirma lo siguiente en cuanto a su primera novela, Gazapo:

Y la novela urbana nace con Casi el paraíso de Luis Spota, El sol de octubre de Solana, y La región más transparente de Carlos Fuentes. Entonces yo era un joven estudiante de preparatoria, y estaba imbuido de la idea de que tenía que escribir sobre la revolución si quería ser escritor. Sin embargo, yo no vivía en el campo: vivía en las calles del Distrito Federal, y sobre esta realidad, que era la mía, tendría que escribir algún día. ${ }^{6}$

Las palabras claves "que era la mía" son prácticamente un código connotativo en las novelas de Sainz. La ciudad no es realmente notable como fenómeno. En Gazapo, por ejemplo, sí reconocemos la localidad y experimentamos la cualidad íntima de un reencuentro entre amigos. Por otro lado, no experimentamos el efecto heroico o épico comunicado por la idea de la ciudad en La región más transparente. En esta novela, Fuentes emplea estrategias narrativas en la transformácion de la historia que desarrollan el concepto heroico. Las estrategias empleadas por Sainz en la narración de Gazapo producen una afinidad entre el lector y un número muy reducido de personajes, sin crear ninguna sugestión de la gran urbe mítica. La ciudad en las novelas de Sainz tiene una cultura propia. No es el lugar a donde muchas personas traen sus variadas culturas de provincia, sino el lugar en que el autor y sus personajes basan su realidad.

Tomemos a Sainz como ejemplo de una generación (o de una promoción) de escritores endeudados con Fuentes en cuanto a la importancia de la ciudad en la novela pero distintos de él en lo que se refiere a la naturaleza funcional de la ciudad. La realización de esta diferencia en la historia sugiere otra pregunta relacionada que podemos plantear: en las otras novelas de ambos autores, ¿tendrá importancia la diferencia que hemos notado en la conceptualización de la historia?

Ya subrayamos la afirmación de Fuentes respecto a la visión del mundo con la cual inicia una novela. Tomando en cuenta todas las novelas de Fuentes, se observan grandes variaciones en la relación entre la realidad extratextual y la historia. En lo que se refiere a esta relación, es interesante observar que $L a$ región más transparente se asemeja más a sus hermanas más recientes que a las

6 Josefina Millán, "Gustavo Sainz: el humor o el suicidio", Diorama de la Cultura, suple. de Excelsior (24 de noviembre de 1974), p. 4 (énfasis mí). 
más cercanas. Conviene destacar dos líneas entre las novelas de Fuentes, en lo que se refiere a la conceptualización de la historia. En la línea "A" se encuentran novelas de las cuales el referente es una realidad reconocible y representada en la historia-La muerte de Artemio Cruz, Las buenas conciencias y probablemente La cabeza de la hidra. Conviene aclarar que el fenómeno al cual nos referimos no tiene que ver con las estrategias que el narrador emplea para transformar la historia sino con la conceptualización de ésta. La realidad extratextual de La muerte de Artemio Cruz, por ejemplo, es una realidad mexicana reconocible. El factor más importante de esta realidad es la vida de un ex-revolucionario. Si Artemio Cruz fuera una persona real, la historia del libro sería su biografía y correspondería exactamente a su referente. Puesto que Artemio Cruz es una invención de Fuentes, entendemos que la historia es una invención paralela a la realidad extratextual. Esta invención paralela es transformada luego por el narrador, mediante el conocidísimo punto de vista variable y otras estrategias, para hacer la narrativa que leemos.

En la línea "B" hay novelas muy distintas porque el factor más importante de su realidad extratextual no es la vida cotidiana sino una idea o un concepto-Aura, Cumpleaños, Una familia lejana y posiblemente Zona sagrada. Se debe observar que la historia, en estos casos, no es una representación de la realidad cotidiana sino una ejemplificación del concepto. Claro que hay personajes y actos reconocibles que funcionan en la narración, pero lo que le interesa al lector es el ingenioso desarrollo del concepto, no la caracterización como en el caso de Artemio Cruz. Tales narrativas son más conceptistas que novelescas, en el sentido tradicional del término.

También hay novelas de Fuentes que combinan las líneas " $A$ " y " $B$ ". No se trata de una línea " $C$ " sino de una tensión entre la tendencia representacional y la tendencia conceptista-Cambio de piel, Terra Nostra y yo agregaría La región más transparente. Recordamos que Fuentes afirmó, en la entrevista con Carballo, que al iniciar una novela tiene "una visión del mundo" y que, en La región..., manipula a sus personajes para ejemplificar ese mundo. Ocurre, en las tres novelas aquí citadas, que hay caracterizaciones interesantes pero no son más importantes que los conceptos desarrollados. En consecuencia, el lector cooperativo tiene que ajustarse a la combinación de dos complejos de expectaciones, uno que se refiere a una serie de acciones basadas en un conflicto y que terminan en un desenlace, y un segundo complejo que se refiere a la exposición de un concepto.

Lo que hemos observado en la obra de Fuentes indica la existencia de una tensión entre dos tipos de narrativa. La tensión no es necesariamente una condición que existe entre autores ni aun entre libros sino en una misma novela. Estudiemos ahora lo que pasa en las novelas de Sainz. 
En sus tres novelas posteriores a Gazapo, la definición de la ciudad como la realidad que es "la mía"--desde el punto de vista del autor--nunca pierde importancia, pero esta manera de apreciar la ciudad no es el factor más importante de la realidad extratextual. Esta realidad-es decir, el referente-es extraordinariamente rica en Obsesivos días circulares. Desde un principio, reconocemos la presencia del Ulises, de Joyce. No se trata solamente de una mención eventual sino de un factor del referente. Al lado de este factor y otros de menos importancia, la vida de un joven en la ciudad de México surge como el elemento más importante. Pero Terencio no es un joven cualquiera-o si lo es, se trata de una generación muy idiosincrática. Terencio es un joven de percepciones fragmentadas, cuya personalidad exige el empleo de una expresión nortea mericana, ya que él no es capaz de "get it all together". Sobra decir que la transformación de la historia se efectúa mediante muchas estrategias que desarrollan esta característica, con frecuente ironía. Sin embargo, se debe notar que esta cualidad personal es una parte de la historia. En la conceptualización de esta historia, Sainz modifica la realidad extratextual para tratar de un tipo predeterminado, con cierta ironía. Evidentemente, la relación entre la realidad extratextual y la historia en esta novela es ambigua. Se pudiera decir que el referente-o un aspecto muy importante del referente--es un joven del tipo Terencio. Por otro lado, conviene pensar en un referente que es la ciudad de Mexico moderna, modificada en la historia mediante un concepto que impone la idiosincrasia de Terencio.

La princesa del Palacio de Hierro es probablemente la novela más "conceptista"-si me permiten seguir empleando esta palabra--que ha escrito Sainz. El mundo que experimentamos en esta obra es matizado por una mujer cuya caracterización se basa en su manera de hablar. Habría justificación para afirmar que el referente, la realidad extratextual, de esta novela fuera una manera de hablar. Se nota que por eso La princesa ... se asemeja a las novelas de la línea " $B$ " en la obra de Fuentes, en las cuales no hay diferencia substancial entre la historia y la realidad extratextual. La comparación puede parecer absurda, dado lo intencionadamente cursi de la novela de Sainz. Tiene validez en lo que se refiere al acto de comunicación. Naturalmente, la semejanza no es cien por ciento, ni mucho menos, ya que se observa fácilmente la complejidad del referente. Por otro lado, el contraste entre el fenómeno en Obsesivos días ... y en La princesa ... sirve para indicar la variabilidad, en la obra de Sainz, en cuanto a la conceptualización de la historia.

Compadre Lobo, la novela más reciente de Sainz, interesa por su referente tan obvio--el artista de antecedentes humildes, en la ciudad de México. La conceptualización de la historia depende, en gran medida, de la focalización, fenómeno que normalmente se estudia como una de las estrategias empleadas en la transformación de la historia, no en la conceptualización de ella. Sin 
embargo, parece que en esta novela, la fuente de información (cómo el narrador obtiene la información que narra) es un factor predeterminado en la historia.

Comparadas con la obra de Fuentes, las novelas de Sainz se asemejan más a la combinación de las líneas "A" y "B". La línea representacional predomina sobre la conceptista, pero la segunda tendencia siempre está presente. Se aprecia la tendencia conceptista, desde Gazapo hasta la obra más reciente, en cierta conciencia del acto de hacer una ficción y en un tono humorístico, hasta juguetón. Por otro lado, es evidente que los personajes de Sainz viven en el mundo que experimentamos todos los días y que, dentro de la narrativa, hacen más que ejemplificar conceptos.

Se puede afirmar que se destacan dos fenómenos en las novelas de Sainz, ambos relacionados con la transformación efectuada entre la realidad extratextual y la historia; (1) la ciudad como seña de identidad y (2) la tensión entre una historia representativa y una historia conceptista. Me atrevo a afirmar que estos fenómenos son dos características evidentes en la novela mexicana de la actualidad - con la advertencia de que la tensión se experimenta a veces en una sola novela y otras veces entre novelas de dos tendencias distintas. Cualquiera que sea su formato, la tensión en el acto artístico corresponde, a mi juicio, a una tensión social entre el procedimiento y la substancia. 